\title{
A Case of a Gallbladder Infarction after Transcatheter Arterial Chemoembolization, Recovered with Only Medical Treatment
}

\author{
Yena Kang', Eun-Jung Kim', Young Seok Kim', Sang Gyune Kim', Jae Myeong Lee², Boo Sung Kim \\ Departments of ${ }^{1}$ Internal Medicine and ${ }^{2}$ Radiology, Soonchunhyang University Bucheon Hospital, Bucheon, Korea
}

\begin{abstract}
Transcatheter arterial chemoembolization (TACE) is suitable treatment method of hepatocellular carcinoma (HCC) for patients with decreased underlying liver function or unresectable disease. But this procedure can induce some embolic events. We report a case of a gallbladder infarction caused by the embolic event in TACE procedure. A 61-year-old man had been going to undergo 6th TACE for marginal recurrence of HCC. After the procedure, gallbladder infarction occurred and was detected by abdominal computed tomography (CT) scan for response evaluation of the treatment at out-patient-clinic. Then, he was treated with oral antibiotics and conservative therapy at out-patient clinic. In 6th week after the event, abdominal CT scan showed improved state of gallbladder.
\end{abstract}

Keywords: Gallbladder; Hepatocellular carcinoma; Embolism

\section{INTRODUCTION}

Hepatocellular carcinoma (HCC) is the 5th most common cancer in South Korea. And it is the 4th most common cancer in Korean men and 6th most common cancer in Korean women [1]. Most preferred treatment is surgical resection. Even though that, many patients with extended disease or decreased liver function are inappropriate for surgery.

Transcatheter arterial chemoembolization (TACE) is suitable treatment for these patients. Recently TACE is commonly used treatment method for HCC, because of its execution time saving and wide indications. It could be applicable for patients with distant lesions from each other, huge sized tumor or decreased liver function. But there are some complications. The risk of embolic events caused by therapeutic embolic materials is one of those in the treatment.

\section{CASE REPORT}

A 61-year-old man, who already had been treated with 5 times of TACE, went to undergo 6th procedure. He was treated by TACE for 6 times during 6 years. Last TACE was planned to be done for marginal recurrence and remnant viable portion of HCC at S6 and S8 (Fig. 1).

During the procedure, adriamycin $(50 \mathrm{mg})$ and lipiodol $(5 \mathrm{~mL})$ mixture was infused via feeding branch of right hepatic artery. No gelfoam embolization was done due to injured intrahepatic arteries (Fig. 2). Immediately after the TACE, he complained of abdominal pain in right-upper-quadrant. And next day of procedure, the patient felt nausea and chilling sense. Fever sustained three days and body temperature rose to $39^{\circ} \mathrm{C}$. Abnormal liver functions were seen. Serum levels of aspartate aminotransferase and alanine aminotransferase were checked up to $179 \mathrm{mg} / \mathrm{dL}$ (normal value, 5 to $40 \mathrm{IU} / \mathrm{L}$ ) and $231 \mathrm{mg} / \mathrm{dL}$ (normal value, 0 to $40 \mathrm{IU} / \mathrm{L}$ ). White blood cell count was elevated to $11,490 / \mathrm{uL}$ (normal value, 4,000 to $10,000 / \mu \mathrm{L})$. Antipyretics and analgesics were administered to him. The treatment made symptoms and fever decreased but not removed. He was discharged 6th post-procedural day.

In out-patient clinic, still he was suffering from that pain. And then we took the follow-up computed tomography (CT) image for response evaluation and there were abnormal findings on gallbladder. Gallbladder was distended and linear air density was seen
Correspondence to: Yena Kang

Department of Internal Medicine, Soonchunhyang University Bucheon Hospital, 170 Jomaru-ro, Wonmi-gu, Bucheon 14584, Korea

Tel: +82-2-336-2079, Fax: +82-2-336-2079, E-mail: twinkling-star@nate.com

Received: Sep. 24, 2015/ Accepted after revision: Oct. 7, 2015
(C) 2015 Soonchunhyang Medical Research Institute This is an Open Access article distributed under the terms of the Creative Commons Attribution Non-Commercial License (http://creativecommons.org/licenses/by-nc/3.0/). 

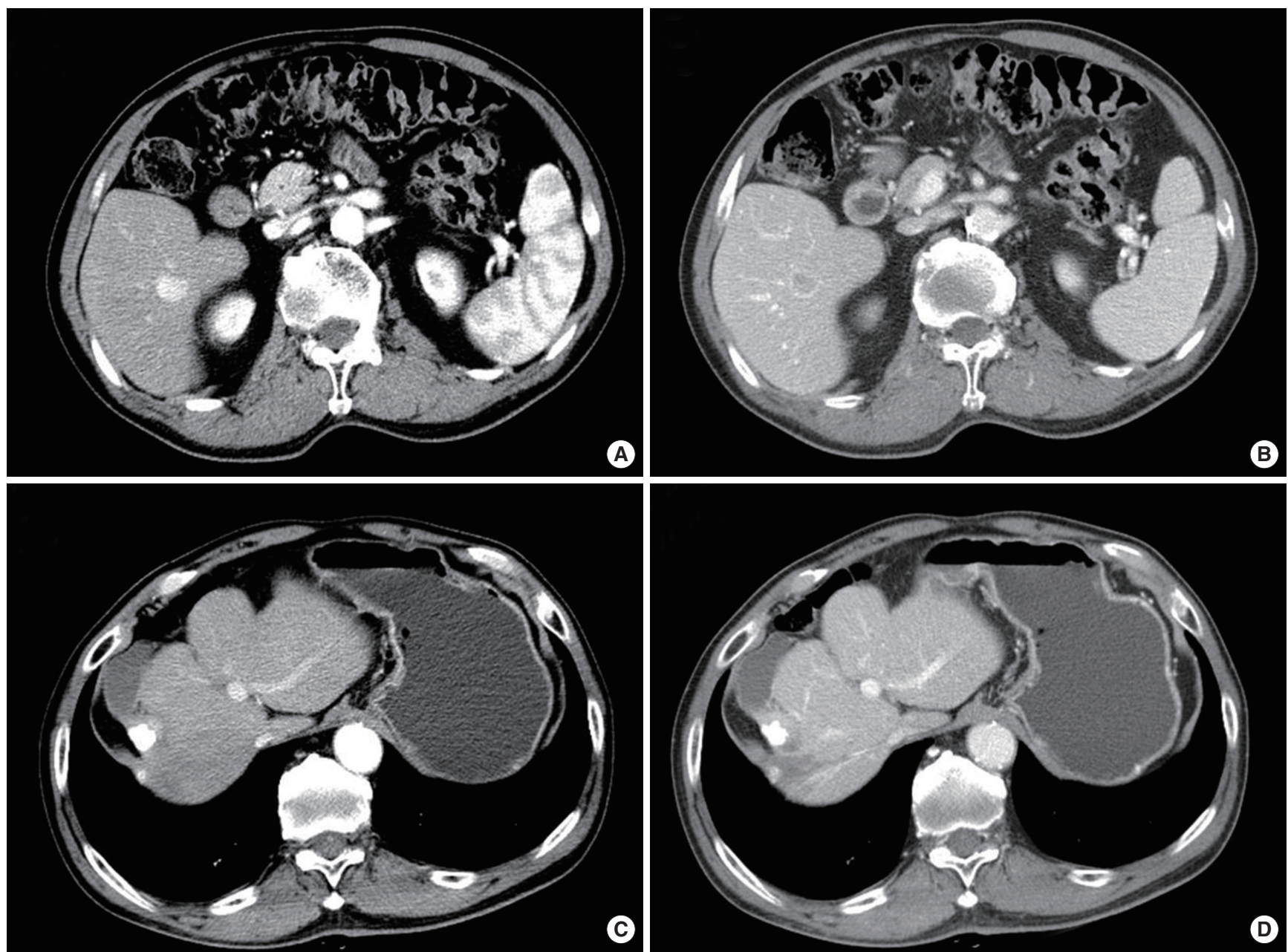

Fig. 1. (A, B) Marginal recurred HCC in seen at lateral aspect of lipiodol uptaken HCC in S6 and (C, D) transient enhancing lesion in shown at inferomedial portion of lipiodl uptaken HCC at S8. HCC, hepatocellular carcinoma.
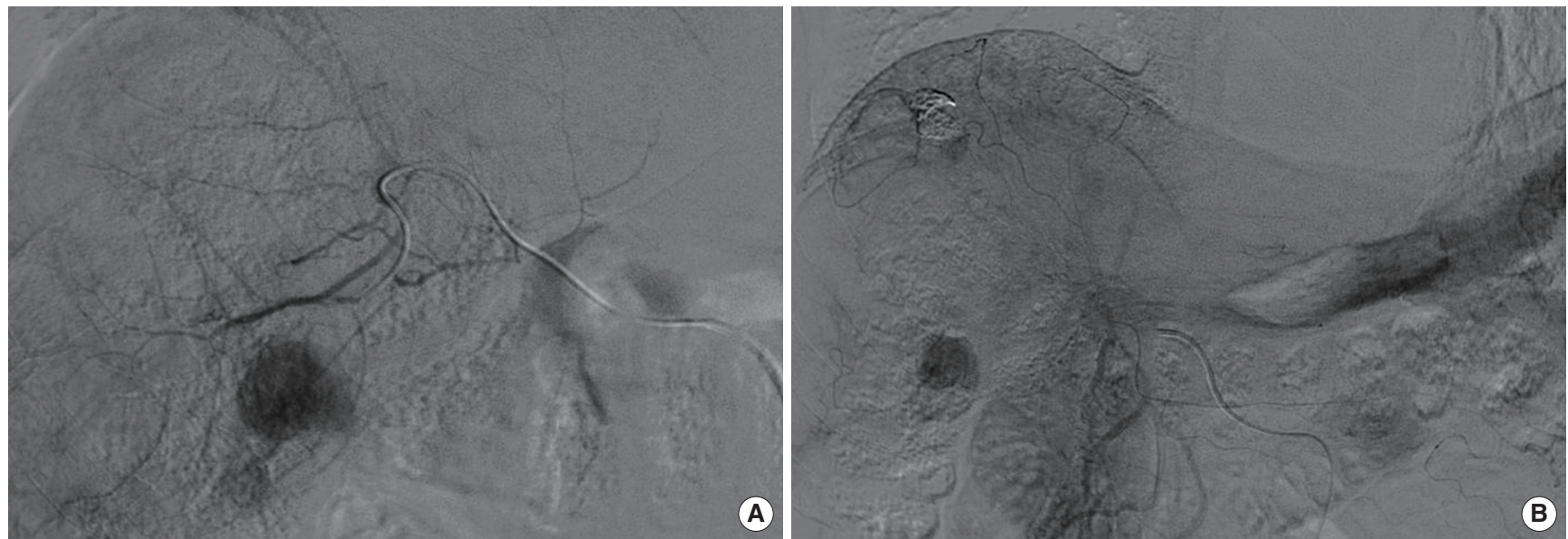

Fig. 2. (A, B) Adriamycin $(50 \mathrm{mg}$ ) and lipiodol (5 mL) mixture infusion was done via feeding branch of right hepatic artery. No gelfoam embolization was done due to injuried intrahepatic arteries. 

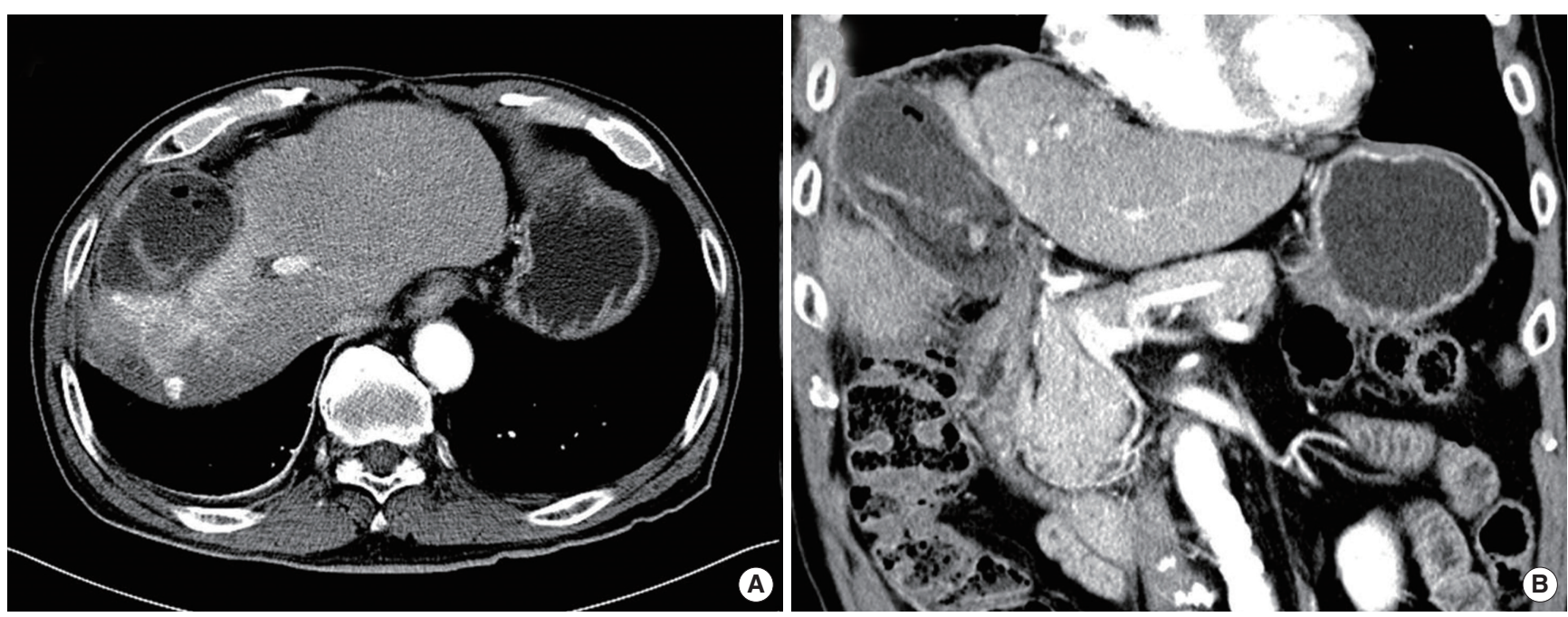

Fig. 3. (A) Distended gallbladder had wall thickening and linear air density was seen below the enhanced wall. (B) Infarcted gallbladder is seen at coronal section.

below the enhanced thick wall (Fig. 3). These clinical signs and symptoms suggested gallbladder infarction caused by the embolic event during chemoembolization. Then we used oral antibiotics (cefditorene) and analgesics (acetaminophene) for 12 days. After the treatment, the patient felt better, and some improvement was seen in CT image, taken at 6th week after the event. CT image showed decreased volume of gallbladder infarction and disappearance of air bubbles. Also patient's symptoms are resolved.

\section{DISCUSSION}

HCC presents multi-centric carcinogenesis and intrahepatic metastasis, because most of HCC cases have underlying liver diseases (e.g., chronic viral hepatitis, alcoholic liver disease). HCC frequently recurs after primary treatment and it is even often multifocal. TACE has been widely used as a treatment for multifocal HCC in patients, in whom curative treatment is difficult to perform [2]. Also it can be applied to patients with poor liver function or multiple lesions. Thus the Barcelona Clinic Liver Cancer staging system recommends TACE for intermediate-stage HCC (four or more tumors), and the Japan Society of Hepatology consensus recommends TACE for patients with a Child-Pugh score A or B, tumor diameter of more than $3 \mathrm{~cm}$, or four or more tumors $[3,4]$.

Therapeutic effect of TACE is based on the phenomenon, which is that, advanced HCCs are fed only by the hepatic artery and is intended to embolize the distal portion of the hepatic artery [5]. In contrast, it contains aspect of risk such as systemic embolization.

In the past, some cases were reported. They referred to gallblad- der infarctions caused by preoperative hepatic artery embolization with gelfoam. Preoperative hepatic artery embolization is performed to decrease the vascularity and size of the HCC before operation and to prevent intrahepatic spread during surgery [6,7]. In our case, surgery was not considered and we use only lipiodol without gelfoam. Not only gelfoam, but also Lipiodol has embolic risk. Pulmonary, cerebral, and biliary embolisms caused by lipiodol were reported $[5,8,9]$. Sometimes, embolic event is only a mild feature, but some reports mention about biliary necrosis, which requires surgical treatment or some invasive interventions like percutaneous drainage [8]. When embolic material plugs the cystic artery, irreversible ischemic complication can be developed. Furthermore, compared to liver, the gallbladder is supplied from only cystic artery. So gallbladder is vulnerable to this ischemic event.

After TACE, nausea, vomiting, fever, and right upper quadrant pain are frequently present. This symptoms and signs are called as postembolization syndrome. It usually recovers spontaneously [5]. But this is similar to clinical features of the gallbladder embolism. Therefore, following-up of patient's symptoms and laboratory values such as inflammatory markers is important to differential diagnosis and as in this case, image studies are useful.

Furthermore, this patient has recovered with only pharmacologic treatment. Early start and maintenance of antibiotics could have prevented for worsening of necrosis.

\section{REFERENCES}

1. Yoon SK, Chun HG. Status of hepatocellular carcinoma in South Korea. 
Chin Clin Oncol 2013;2:39.

2. Imai N, Ishigami M, Ishizu Y, Kuzuya T, Honda T, Hayashi K, et al. Transarterial chemoembolization for hepatocellular carcinoma: a review of techniques. World J Hepatol 2014;6:844-50.

3. Bruix J, Sherman M; American Association for the Study of Liver Diseases. Management of hepatocellular carcinoma: an update. Hepatology 2011;53:1020-2.

4. Arii S, Sata M, Sakamoto M, Shimada M, Kumada T, Shiina S, et al. Management of hepatocellular carcinoma: report of Consensus Meeting in the 45th Annual Meeting of the Japan Society of Hepatology (2009). Hepatol Res 2010;40:667-85.

5. Vogl TJ, Naguib NN, Nour-Eldin NE, Rao P, Emami AH, Zangos S, et al. Review on transarterial chemoembolization in hepatocellular carcinoma: palliative, combined, neoadjuvant, bridging, and symptomatic indica- tions. Eur J Radiol 2009;72:505-16.

6. Takayasu K, Moriyama N, Muramatsu Y, Shima Y, Ushio K, Yamada T, et al. Gallbladder infarction after hepatic artery embolization. AJR Am J Roentgenol 1985;144:135-8.

7. Kuroda C, Iwasaki M, Tanaka T, Tokunaga K, Hori S, Yoshioka H, et al. Gallbladder infarction following hepatic transcatheter arterial embolization: angiographic study. Radiology 1983;149:85-9.

8. Jung G, Kim JW, Joe JH, Kim SJ, Lee JB, Kim JG, et al. A case of necrotizing liver abscess and bile duct necrosis following hepatic arterial chemoembolization in hepatocelluar carcinoma. Korean J Hepatol 1999;5:348-52.

9. Matsumoto K, Nojiri J, Takase Y, Egashira Y, Azama S, Kato A, et al. Cerebral lipiodol embolism: a complication of transcatheter arterial chemoembolization for hepatocellular carcinoma. Cardiovasc Intervent Radiol 2007;30:512-4. 